\title{
Gubernamentalidad y resistencia al neoliberalismo en la obra de Michel Foucault. Una tentativa de liberarnos de nosotros mismos
}

\section{[Governmentality and Resistance to Neoliberalism in the Work of Michel Foucault. An Attempt to Free Us from Ourselves]}

\author{
HERO SUÁREZ RUIZ \\ École Supérieure de Sciences Économiques et Commerciales (ESSEC), París \\ herosuarez@gmail.com
}

\begin{abstract}
Resumen: En este artículo abordo las relaciones entre la subjetividad y la gubernamentalidad en la obra de Michel Foucault con la finalidad de profundizar y elucidar ciertos elementos que subyacen en su estrategia para escapar de las formas de subjetivación neoliberales. La subjetividad se piensa como la tensión entre un dispositivo de control y un lugar para la resistencia. Su estrategia se funda en la comprensión de los procesos de estatalización y de las prácticas estatales a partir de las cuales podemos entender cómo hemos llegado a ser lo que somos y con ello resistir a los procesos de subjetivación que fomentan dichas prácticas.
\end{abstract}

Palabras clave: subjetivación, estatalización, cuidado de sí, inservidumbre, población

\begin{abstract}
This article examines the relations between subjectivity and governmentality in the work of Michel Foucault in order to clarify the elements involved in his strategy to escape from neoliberal forms of subjectivation. Thus, I examine how subjectivity emerges from the tension between being a control device and at the same time a place of resistance. Foucault's strategy is based on the understanding of processes of nationalization and State practices, from which we might understand how we have become what we are and, on this basis, resist the processes of subjectivation promoted by state practices.
\end{abstract}

Key words: subjectivation, statalization, self-care, helplessness, population

\section{Introducción}

Vivimos en una época de seguridad en comparación con todas las anteriores; no obstante, se trata del periodo histórico en el que hay más población y más estructuras penitenciarias en el mundo. Por ejemplo, en Francia, como informa Didier Fassin, en menos de sesenta años la población penitenciaria se ha multiplicado por tres y medio, con lo que alcanzó en 2016 un récord con cerca de setenta mil prisioneros. ${ }^{1}$ Por

\footnotetext{
${ }^{1}$ Fassin 2017b (pp. 9-17 y 162), explica cómo en los últimos cincuenta años han aumentado las personas encarceladas por delitos menores, mientras que los homicidios dolosos han disminuido.
} 
otra parte, en la población penitenciaria de los países con un mayor índice de desarrollo capitalista algunas minorías están sobrerrepresentadas, las cuales son al mismo tiempo las que tienen mayores posibilidades de tener vidas precarias. En resumen, como demuestra Fassin 2018, han aumentado las vidas que valen menos. ${ }^{2}$ Esas vidas que valen menos, como señala Foucault, son excluidas de los beneficios del sistema y sirven como una eficiente forma de control.

En este mismo sentido, a pesar de tener una de las ciudadanías más dóciles de la historia de la humanidad y de una supuesta reducción del Estado en favor del mercado, hoy los controles son cada vez más exhaustivos y los Estados aumentan de manera constante sus capacidades para controlar la ciudadanía en todos los niveles. Las formas de resistencia al sistema se han multiplicado y fragmentado. De las que más se habla son de las que sirven como justificación a los Estados para aumentar su capacidad omnisciente sobre nuestras vidas, ${ }^{3}$ a las cuales gestiona mediante dispositivos y discursos que dan forma a las subjetividades, a la vez que suscitan las posibilidades de resistencia a los mismos. Se trata de resistencias en las que podríamos encontrarnos a nosotros mismos pues, como veremos, la subjetividad en Foucault es el terreno por el que transita el poder y el lugar desde el que se lo puede resistir.

${ }^{2}$ En relación con el valor distinto de las vidas humanas en las sociedades contemporáneas y con esas vidas que valen menos, cfr. Fassin 2018. En esa obra Fassin discute el concepto de "biopolítica" de Foucault para idear uno propio, el de "políticas de la vida", y concluye que ciertas vidas en las sociedades actuales se tratan como si valieran menos que otras en función de ciertos rasgos culturales que se consideran biológicos. Esto es, en su física de las desigualdades, que contrapone a la metafísica de la alteridad levinasiana, determina que hay vidas que valen menos debido a las jerarquías prestablecidas que determinan las relaciones sociales y que permiten que se subestimen unas vidas mientras que se favorecen otras. Esas vidas que valen menos son en parte las que encontramos en las prisiones, en los centros de internamiento de inmigrantes; son las vidas de los refugiados, de los parados, de las mujeres, de los indígenas y de todos aquellos que podemos llamar "subalternos". Así, el sintagma de vidas que valen menos en el marco de las "políticas de la vida" se encamina, según Fassin, a ir más allá de la expresión de la compasión para presentarse como el reconocimiento de una injusticia.

${ }^{3}$ En esto concuerdo con el Comité Invisible. Este colectivo sugiere que los atentados recientes en Francia son fruto de la confusión que provocan las formas de control difusas de las que habla Foucault y, en este sentido, defienden la idea de que "esos que reivindican los atentados y también los que llaman a la guerra contra los mismos quieren que nos confundamos, mientras que quienes los ejecutan son los hijos de esa confusión" (Comité Invisible 2017, pp. 14-15; a menos que se indique lo contrario, las traducciones son mías). 
Así, mi artículo se ocupa del concepto de gubernamentalidad y de sus relaciones con la subjetividad en la obra de Michel Foucault y propone una interpretación de la misma que busca alumbrar resistencias potenciales a las formas de subjetivación neoliberales que pretenden concebirnos como emprendedores y emprendedoras de nosotras mismas. Uno de los elementos que define a las sociedades modernas es el hecho de que han desarrollado de manera creciente mecanismos para regular la existencia de los seres humanos. Según Foucault, esta regulación de la existencia, o biopoder, es un elemento indispensable en el desarrollo del capitalismo y es lo que da forma a la biopolítica que hoy padecemos en su versión neoliberal. Así, con un interés mayor por la obra que por el autor, propongo una lectura de la primera que se aleja de la corriente que acerca la obra Foucault a la promoción de las tesis neoliberales con la intención examinar las posibilidades de oponer resistencia a la forma de comprender el mundo neoliberal que, en mi opinión, es hegemónica en el mundo occidental. ${ }^{4}$ Para ello, exploraré primero la manera en la que se estructura la obra de Foucault y cómo se abordan en ella los problemas. Después analizaré cómo se presenta el Estado moderno en su paso de la soberanía a la gubernamentalidad para exponer las modificaciones que se producen con la introducción de la biología como elemento de político y que hacen surgir al Estado de población, que a su vez allana el camino para que el mercado devenga el principal parámetro de la veridicción. Tras esta lectura de Foucault, insistiré en los caminos que abre para pensar las formas de resistencia a las formas de subjetivación neoliberales.

\section{La estrategia: de la arqueología a las técnicas de subjetivación}

Foucault parte de la idea de que su análisis es un intento de construir una ontología de la actualidad. De manera similar al intento kantiano de indagar sobre el significado de la Ilustración como una tentativa de actualizar el presente, él se pregunta por los discursos que hacen que unas prácticas concretas sean válidas en su tiempo. Esto lo lleva a

\footnotetext{
${ }^{4}$ Algunos críticos de Foucault, como Vargas 2014 o De Lagasnerie 2012 plantean que Foucault se siente atraído por el neoliberalismo y que, por tanto, lo defiende, a pesar de que históricamente la izquierda se haya apropiado de su pensamiento. Frente a tales argumentos, el presente texto piensa la obra de Foucault, aunque con matices, desde una perspectiva más próxima de Christian Laval, para quien el análisis del neoliberalismo que realiza Foucault puede servirnos para inventar una nueva política que permita combatir el modo del poder actual (Laval 2018, pp. 126-129).
}

Revista de Filosofía Diánoia, vol. 65, no. 85 (noviembre de 2020-abril de 2021) e-ISSN: 1870-4913 • DOI: https://doi.org/10.22201/iifs.18704913e.2020.85.1845 
analizar el proceso de racionalización de los discursos veridiccionales o, dicho de otra manera, de los discursos que crean verdades y racionalizan las prácticas en su presente - aunque no en el presente en un sentido cronológico, sino en el de su época, en la modernidad (Foucault 2004b, pp. 36-38, y Foucault 2008, p. 22) —, con la finalidad de elaborar una ontología de nosotros mismos con la que se pueda articular en forma discursiva un presente susceptible de ser cambiado (Foucault 2001a, texto 84 y Foucault 1994b, pp. 679-688).

Para realizar tal cometido, Foucault orienta sus reflexiones hacia la identificación y explicación del espacio de surgimiento de los discursos que crean verdades. Los discursos de los que se ocupa son aquellos que construyen caminos de los que se no se puede salir y que terminan por dar forma a los procesos de explotación y de sumisión en la medida en que moldean la subjetividad de los individuos que circulan por ellos. Analiza las prácticas estatales para "romper con las cosas con las que aún podemos romper para hacer de la libertad un problema estratégico, para crear libertad, para liberarnos de nosotros mismos" (Morey 2014a, p. 334), lo que sólo podrá realizarse mediante la comprensión de y la resistencia $a$ las modalidades a través de las cuales el poder se introduce en los cuerpos de los individuos y da forma a las subjetividades.

Como señala Miguel Morey, los estudios sistemáticos sobre la obra de Foucault suelen distinguir tres periodos cronológicos según los métodos que utiliza y los temas que abarca (Morey 2014a, pp. 312-313). El primer periodo es en el que se ocupa del binomio saber/poder con el método arqueológico. Con este método podemos decir que se dedica a identificar los espacios en que aparecen los discursos que dan forma a ese binomio. En el segundo periodo adopta el método genealógico para explicar cómo se han formado los espacios identificados que darán forma a los discursos. El tercer periodo se ocupa de las técnicas de subjetivación que surgen de los discursos identificados y explicados antes. En este sentido, los textos en los que se ocupa del Estado pertenecen a los periodos de la genealogía y el de las técnicas de subjetivación, y se publicaron en la serie de los cursos que van desde 1970 hasta su muerte en 1984. En los cursos que van desde 1970 hasta 1975 se ocupa sobre todo de la constitución de los mecanismos disciplinarios, y no es sino a partir de 1975 que la biopolítica aparece como uno de los ejes sobre el que giran sus reflexiones sobre el Estado para, a partir de 1980, comenzar a referirse a las técnicas de subjetivación.

A pesar de dichas distinciones analíticas, lo cierto es que, al menos en sus reflexiones sobre el Estado y las subjetividades contemporáneas, el biopoder y la sociedad disciplinaria, al igual que los métodos arqueo- 
lógicos y genealógicos, no desaparecen una vez que la biopolítica y las técnicas de subjetivación se convierten en un paradigma estratégico de gobierno y centro de su reflexión, sino que se complejizan y se imbrican entre ellos. Incluso en una de sus últimas intervenciones, el propio Foucault hace referencia a las tres etapas y declara que su meta siempre fue la misma: crear una historia de los diferentes modos de subjetivación del ser humano en la cultura occidental (Foucault 1994b, p. 208). A su vez, al publicar la obra póstuma Il faut défendre la société, Alessandro Fontana y Mauro Bertani también señalan que Foucault nunca dejó de releer sus trabajos iniciales para reactualizarlos constantemente (Foucault 2004b, p. 248). En este sentido, mi lectura de la obra de Foucault la concibe como un todo; de ahí que, aunque me refiera sobre todo a la segunda y tercera partes que identifica la crítica, me ocuparé de los conceptos y reflexiones de los tres periodos por igual.

El concepto de Estado: de la soberanía a la gubernamentalidad

Para Foucault, el problema político fundamental de la modernidad es el de pensar en una multitud de fuerzas que actúan e interactúan entre ellas para generar relaciones de obediencia y mandatos imperativos (Lazzarato 2000, pp. 45-57). Por ello, analiza el sentido del origen de los procesos y mecanismos que dan forma a los actuales Estados y a sus formas de racionalidad en las que se han integrado parte de esa multitud de fuerzas. La concepción que resulta de su análisis sostiene que los Estados actuales son entidades políticas gestionadas por discursos neoliberales que generan verdades sobre la base de axiomas economicistas, a la vez que dan forma a las subjetividades para producir, según los términos de Foucault, sujetos destinados a ser emprendedores y emprendedoras de sí mismas. ${ }^{5}$

Tales axiomas surgen en un proceso que se inicia en el siglo XVIII y aparecen acompañados de un cambio de paradigma en la concepción del poder político. En esa época se pasa de un poder destinado a ejercer la soberanía sobre un territorio a otro que se proponía garantizar la seguridad de una población y la obediencia voluntaria de los individuos a partir de la creación de un conocimiento que los objetiva. La creación de este conocimiento es inherente al proceso de estatización que da paso a la modernidad política y conduce a los individuos a objetivar su propio yo para constituirse en sujetos mediante su vinculación con

${ }^{5}$ En su curso del 14 de marzo de 1979 afirma que "En el neoliberalismo [...] encontramos una teoría del homo oeconomicus [...]. El homo oeconomicus es un emprendedor y un emprendedor de sí mismo" (Foucault 2004b, p. 232).

Revista de Filosofía Diánoia, vol. 65, no. 85 (noviembre de 2020-abril de 2021) e-ISSN: 1870-4913 • DOI: https://doi.org/10.22201/iifs.18704913e.2020.85.1845 
un poder exterior que los considera especie humana (Agamben 1995, p. 129).

Foucault sostiene que a lo largo de la historia de Occidente se produce un desplazamiento mediante el cual la vida biológica de los individuos se convierte en un espacio de acción política gracias a un patrón determinado por los casos individuales y concretos. El Estado lo concibe como una creación histórica producto de las prácticas de gobierno. Para Gilles Deleuze, en la obra de Foucault "No hay Estado, sino solamente estatización" o, en la terminología de Foucault, lo que hay es gubernamentalización, no un Estado sobredimensionado. Este desplazamiento de la atención hacia las características biológicas de los individuos y hacia las prácticas gestoras estatales que inciden sobre ellas es lo que Foucault denomina "biopolítica" (Deleuze 2004, p. 82) ${ }^{6}$

No obstante, a pesar de que la forma de Estado haya capturado una gran cantidad de relaciones de poder y sea expresión de las mismas, éstas no derivan del Estado, sino que se imbrican con él durante el proceso de gubernamentalización. Foucault no incurre en la fobia del Estado propia de los neoliberales, sino que analiza cómo los discursos neoliberales dirigen los procesos de gubernamentalidad. Dicho proceso es muy variable y produce diferentes dominios, como pueden ser el orden pedagógico, judicial, económico, familiar y sexual, que determinan los comportamientos de los sujetos. Por ello, en su obra se plantea que la comprensión de tal proceso nos permitirá resistirnos a ellos.

\section{Gubernamentalidad y biopoder}

Para Foucault, lo que determina la característica diferenciadora del Estado moderno es que con su formación se produce un deslizamiento

${ }^{6}$ El término "biopolítica" no es un neologismo de Foucault. Ya desde mediados del siglo XIX aparece en Auguste Comte, en el Système de politique ou traité de sociologie instituant la Religion de l'Humanité, (Comte 1851, pp. 618-619 y 630). Asimismo, el concepto se utilizaba en los años sesenta del siglo pasado para hacer referencia a diferentes fenómenos, como muestra el hecho de que Aaron Starobinski titule su libro La biopolitique. Essai d'interprétation de l'histoire de l'humanité et de la civilisation y que Edgar Morin llame al suyo Introduction à une politique de l'homme. Por otra parte, Didier Fassin plantea sobre este asunto que le parece erróneo afirmar que sea la primera vez en la historia que se produce el proceso que Foucault define como el nacimiento de la biopolítica, ya que el Imperio romano y el Imperio inca tenían prácticas similares de control sobre sus poblaciones, aunque también reconoce la importancia de la fecunda intuición de Foucault según la cual las sociedades modernas se caracterizan por el desarrollo de mecanismos destinados a controlar la existencia de los individuos (Fassin 2018, pp. 111-113). 
de la atención de la vinculación del poder con el territorio hacia un "Estado de población" (Foucault 1989, p. 99).

Este paso le hace decir que Maquiavelo, más que ser el autor que inaugura la modernidad política, es uno de los últimos autores de la premodernidad, ${ }^{7}$ ya que el Estado en el pensamiento del florentino se determina por la relación del soberano con el territorio. Se centra en la capacidad del soberano para hacerse temer, amar u odiar por los gobernados con el fin garantizar su soberanía sobre el territorio. En este periodo, el poder se ejerce de manera ceremoniosa sin escatimar en gastos, y pasa necesariamente por el empleo de la violencia directa y espectacular sobre los cuerpos. Baste citar la condena que abre las páginas de Vigilar y castigar. Basado en un archivo, Foucault narra cómo un condenado llamado Damiens es despedazado por cuatro caballos tras padecer diferentes suplicios en la Plaza de Grève -en la que hoy se sitúa el Ayuntamiento de la capital francesa- por haber cometido supuestamente un parricidio (Foucault 1989, p. 99). De ahí que el autor resuma esta forma de gobernar cuando señala que el Estado premoderno se centra en "Hacer morir y dejar vivir", mientras que en el Estado Moderno los términos se invierten para gobernar según el "Hacer vivir y dejar morir". 8

Esos cuerpos sobre los que se ejerce la violencia en los Estados premodernos se piensan como si fuesen máquinas que a su vez forman parte de una máquina superior, a la manera del Leviatán de Hobbes. Sin embargo, en los Estados modernos se los considera cuerpos vivos, con lo que la visión mecánica de la sociedad premoderna se transforma en visión organicista. Esta visión cambia las formas de actuación política, que pasan a centrarse no en las causas, sino en los efectos de los problemas que afectan a la sociedad, lo que se explica por el simple hecho de que es más costoso intentar actuar sobre las primeras que sobre los segundos. Frente a la visión mecanicista que sí que permite

${ }^{7}$ Desde la perspectiva de Foucault (Aron y Foucault 2007 y Foucault 1994b, p. 152), autores como Raymond Aron, Claude Lefort o Ezio Raimondi se equivocan al situar a Maquiavelo en la modernidad porque el florentino no fue más allá del estudio de la soberanía y no reflexionó sobre la gubernamentalidad (Lefort 1972 y Raimondi 1982).

${ }^{8}$ Foucault en el curso del 17 de marzo de 1972, indica que mientras en el paradigma de la soberanía, el soberano cuenta con el derecho sobre la vida y la muerte del súbdito, en el sentido de que podía dejarlo vivir o hacer que se muera, en el contexto de la gubernamentalidad se tratará de hacer que viva y dejarlo morir (Foucault 2004); Giorgio Agamben se vale estas tesis de Foucault para dar cuenta de cómo los Estados actuales se valen de los discursos seguritarios para limitar la democracia, a partir de la lógica de "hacer vivir y dejar morir" (Agamben 2016b). 
ocuparse de las causas - ya que cuando un elemento de la máquina no funciona genera un mal resultado como efecto, así que arreglar esa pieza permite al sistema volver a funcionar-, se pasa a una forma política que se ocupa de los efectos en la medida en que, cuando un organismo funciona mal, sólo nos podemos ocupar de él si atendemos a los síntomas que presenta.

En el curso de 1975, Il faut défendre la société, nuestro autor comienza por interesarse por la guerra civil para después centrarse en la "gubernamentalidad". En un primer momento, sostiene que la política se puede entender si invertimos el aforismo de Clausewitz, y en lugar de pensar que "[1]a guerra no es sino la política por otros medios", plantear que "la política es la guerra por otros medios" (Foucault 1997, pp. 15-17). ${ }^{9}$ Defiende la idea de que la gubernamentalidad y la política moderna son el resultado de un enfrentamiento entre diferentes voluntades de poder que pretenden imponer un estatus concreto, a la vez que hacen del binomio amigo/enemigo la categoría central de la actividad política y, por ende, del Estado resultante. Por ello, en su obra las leyes se conciben como una batalla perpetua y no como un estado de paz, pues gracias a ellas se ejecutan las diferentes estrategias que sirven para garantizar de manera ritual la obediencia. Ahora bien, la inversión de la máxima de Clausewitz y el estudio de las leyes punitivas se dejan de lado en la medida en que la guerra y los castigos permiten pensar las sociedades premodernas, y aunque, como resulta obvio, éstos no desaparecen, sino que se ocultan, sí que pasan a un segundo plano de su reflexión debido a las transformaciones que sufre el Estado entre los siglos XVIII y XIX.

Como afirmé líneas atrás, el Estado en la obra de Foucault no es el totalizador de todas las prácticas a partir de las cuales se ejerce el poder, ya que este filósofo no cree que "el conjunto de los poderes que se ejercen en una sociedad dada - y que aseguran en esa sociedad la hegemonía de una clase, de una élite o de una casta- se resuman por completo en el sistema estatal" (Foucault 2001a, p. 812). Con ello se aleja de las críticas marxistas al Estado que lo reducen a relaciones económicas y hegemónicas. ${ }^{10}$

\footnotetext{
${ }^{9}$ En el curso del 21 de enero de 1976 plantea que el aforismo es anterior a Clausewitz y que éste sólo lo plasma y que, en último término, uno de los primeros pasos para la conformación de los Estados fue la estatización de la guerra (Foucault 1997, p. 41).

${ }^{10}$ Muchos han sido los intentos de vincular el pensamiento de Marx y el de Foucault; sin embargo, como señala Étienne Balibar, a pesar de que hay algunas semejanzas entre Marx y Foucault —ya que este último trabajó sobre los mismos
} 
De la misma manera, entiende que, aunque el Estado tenga el monopolio legítimo de la violencia, no es el único capaz de ejercer esa fuerza o ese poder, debido a que las relaciones de poder son múltiples y se ejercen en redes difusas que se solapan y cambian de campo. El poder se ejerce de manera relacional y no es una sustancia ni algo que se posea. Por ello, termina por reconocer que el análisis de la soberanía no se adapta al sentido en el que él pretende estudiar las relaciones de poder (Foucault 1997, p. 37). Para Foucault, los estudios de la soberanía explican cómo un individuo con capacidades puede y debe devenir sujeto o, mejor dicho, súbdito. ${ }^{11}$ Sin embargo, no se interesan por explicar el espacio y la forma en la que se produce la subjetivación. Para él, son las relaciones de poder las que construyen y dan forma a la subjetividad a partir de la creación de un conocimiento que permite influir sobre las conductas de los gobernados. De ahí que analice la "fabricación de sujetos/súbditos" - y no "la génesis del soberano"- centrándose en los instrumentos técnicos que permiten garantizar y reforzar la soberanía y que tienen como efecto la producción de subjetividades dóciles y obedientes.

Según Foucault, del siglo XVI al XVIII se elaboran discursos que se presentan como una forma de enseñar las artes de gobernar (Foucault 2004a, pp. 91-92). El siglo XVIII es el momento en el que se pasa de manera clara de una forma de racionalidad a otra, ya que si desde el siglo XVI ésta se caracterizaba por diferentes tipos de saber-poder de gobierno que tendían más bien hacia una expansión indefinida de los aparatos —de los sistemas de vigilancia, de administración y de reglamentación-, con la emergencia del liberalismo, expondré más adelante, la economía política se termina por imponer como el principal saber gubernamental y el Estado, en función de ese saber, cede su espacio al mercado, aunque continúa desplegando de manera difusa formas de control, las cuales ahora pasan inadvertidas mientras determinan en forma constante las acciones de los individuos.

Este desplazamiento ocurre debido a las diferentes mutaciones del poder feudal, de las cuales una de las mayores es el surgimiento de las

temas que Marx y que se pueden cruzar idealmente-, ambos ofrecen antropologías incompatibles y un aparato conceptual que otorga diferentes significados a los mismos términos. Ahora bien, esto no impedido al profesor de Nanterre unir sus visiones en su defensa del Ciudadano-sujeto que aparece después de la muerte del sujeto y que, a su modo de entender, podría ser el actor del cambio y creador de nuevas subjetividades (Balibar 2015, pp. 93-95).

${ }^{11}$ Recordemos que, en francés, el término sujet se refiere tanto al sujeto como al súbdito en español.

Revista de Filosofía Diánoia, vol. 65, no. 85 (noviembre de 2020-abril de 2021) e-ISSN: 1870-4913 • DOI: https://doi.org/10.22201/iifs.18704913e.2020.85.1845 
ciudades como entidades modernas. En ellas ya no se busca garantizar la soberanía sobre un vasto territorio, sino de articular las relaciones de las ciudades — que gozaban de cierta autonomía - desde un poder central. Las ciudades modernas plantean problemas económicos y políticos completamente desconocidos hasta entonces y que provocan la aparición de mecanismos nuevos para ejercer el poder vinculados con la categoría de población. Ahora el poder se ejerce sobre los súbditos entendidos como población, como datos empíricos. De esta manera brota una forma novedosa de gobernar mediante la introducción del mecanismo de la seguridad que se introduce con el surgimiento de las ciudades, lo que no es más que un dispositivo biopolítico (Foucault 2004a, pp. 65-66).

Sin embargo, el dispositivo de la biopolítica no remplaza del todo a las antiguas formas de ejercer la soberanía y su violencia directa sobre los cuerpos, ya que el terror se convierte en la gubernamentalidad en estado puro (Foucault 2012, p. 17). Lo que sucede es que simplemente se modifica su función y, en lugar de practicarse de manera ceremoniosa como, por ejemplo, en el pleno centro de la ciudad de París, se ejerce en instituciones del Estado ocultas a la sociedad, como son hoy los centros de retención de inmigrantes o las cárceles masificadas por toda la geografía de la Unión Europea.

\section{El Estado de población}

Desde el siglo XVIII las prácticas estatales se ejecutan mediante técnicas que se fundan en un conocimiento supuestamente científico o veridiccional - la economía política-, que, a su vez, se vincula con un concepto que despolitiza a los individuos, el de "población", (Foucault 2004a, p. 109).

Las categorías relacionadas con la de población (demografía, mortalidad, contagios, inanición, criminología, edad, etc.) y que no caracterizan a los individuos como sujetos políticos, sino como cuerpos biológicos, se emplazan en el centro del ejercicio de las acciones de gobierno. Así, "[e]1 gobierno tendrá [...] una finalidad que se opone de manera clara a la soberanía" (Foucault 2004a, p. 101), y ya no se pretenderá fijar el territorio mediante la guerra, sino establecer formas de control difusas. No se trata ahora de prohibir, sino más bien de anular el fenómeno que produce el peligro, el riesgo o la crisis mediante discursos en torno a la seguridad. Los discursos en torno a la seguridad se comienzan a presentar de tal manera que garantizan la obediencia no mediante la cesión del poder del individuo que pasa a ser súbdito 
del Estado, como en el caso de Hobbes (Foucault 1997, p. 77, y Hobbes 1971), sino mediante discursos veridiccionales que pretenden ser naturales y científicos y que terminan por producir subjetividades particulares (Foucault 1997, p. 68). No se trata ahora de pensar la racionalidad del Estado como un Leviatán producido por átomos individuales que ceden su poder para perseverar en su existencia, sino de pensar que los mecanismos disciplinarios que pretenden garantizar la seguridad y promover la libertad generan sujetos dispuestos a obedecer, aunque ellos no tengan consciencia de ello.

Esta nueva forma de gobernar parte de casos concretos para actuar sobre las poblaciones con la finalidad de encauzar tales efectos en direcciones específicas que pretenden garantizar la obediencia. Pensar en los efectos está determinado por el paso que introduce el discurso sobre la seguridad como argumento para justificar las políticas. Foucault identifica los orígenes del argumento de la seguridad en François Quesnay y los fisiócratas. Sostiene que, tras la publicación del artículo en la Encyclopédie dedicado a los "granos", se produce un cambio de paradigma en las formas de gobernar con el cual la seguridad se vuelve el concepto central para justificar las políticas (Foucault 2004a). El interés por tal artículo surge del hecho de que uno de los problemas más importantes que los los gobiernos tenían que atender era el de la escasez de alimentos. Para afrontar los periodos de escasez, las acciones gubernamentales se centraban sobre todo en la construcción de graneros públicos y en la prohibición de la exportación de semillas. Estas medidas preventivas tenían efectos adversos frente a la producción. Así que lo que propone Quesnay es darle la vuelta al procedimiento: en lugar de intentar evitar las hambrunas y la carestía de alimentos, permitir que se produzcan y, una vez que hayan explotado, intentar gobernarlas mediante el comercio interior y exterior, sin que ello produzca efectos que contravengan la producción. Como señala Agamben, quien sigue para este asunto a Foucault, se trata de gobernar sus efectos en una dirección que interese al Estado mediante el discurso de la seguridad, por lo que ya no hablaríamos de "hacer morir y dejar vivir", sino de "dejar morir y hacer vivir" (Agamben 2016b). ${ }^{12}$

${ }^{12}$ Otro de los casos que cita Foucault es el de las epidemias; en concreto, el de las epidemias de varicela. La manera de gestionarlas parte de los casos concretos con los que se establece de manera estadística la tasa "normal" de contagio y la tasa "normal" de mortalidad provocada. Bajo el supuesto de que no se pueden evitar, a partir del cálculo se dejará morir a la tasa establecida por la estadística y se intentará evitar un contagio mayor separando a los enfermos (Foucault 2004a, pp. 61-65).

Revista de Filosofía Diánoia, vol. 65, no. 85 (noviembre de 2020-abril de 2021) e-ISSN: 1870-4913 • DOI: https://doi.org/10.22201/iifs.18704913e.2020.85.1845 
A pesar de que en el desarrollo de su obra Agamben introduce elementos ajenos a Foucault, los ejemplos que ofrece de esa forma de gobernar que se inaugura con Quesnay pueden ayudarnos a entender el planteamiento foucaultiano. ${ }^{13}$ El filósofo romano explica el mecanismo de seguridad y su inversión a través de las huellas dactilares en los carnés de identidad. El uso de estas formas de identificación —que en un principio servían sólo para identificar a criminales reincidentes y a extranjeros - se ha generalizado en el siglo Xx. Sin embargo, éstas no sirven para prevenir crímenes, sino para volver eficaz la labor del Estado una vez que el crimen ha sido cometido. De ahí que esa práctica gubernamental que pretende garantizar la seguridad de todos conociendo uno por uno a todos los individuos, aparte de convertir a todos y a todas las ciudadanas en criminales en potencia, sólo actúa sobre los efectos y no sobre las causas. ${ }^{14}$ Este discurso en torno a la seguridad lo que pretende es garantizar la obediencia no a partir de la coacción directa, sino poniendo en relación elementos que parecen alejados entre sí, pero de los que se tiene consciencia — gracias al análisis, el cálculo y la reflexión- que actúan sobre la población, pues resulta más eficaz y menos costoso vigilar que castigar y, así, al saberse vigilados por la deseada seguridad, los individuos interiorizan las normas. Mediante esta técnica, los que gobiernan adquieren un conocimiento pormenorizado de los procesos y fenómenos que afectan a los individuos, lo que les permite alterarlos en función de determinados fines. ${ }^{15}$ En este sentido,

${ }^{13}$ En los múltiples volúmenes de su obra Homo Sacer, Agamben desarrolla el concepto de biopoder foucaultiano, aunque, a diferencia de Foucault, lo coloca en el paradigma de la soberanía, que para éste es el que da paso al de la gubernamentalidad. Mientras que en la obra de Foucault el poder se modifica cuando toma la vida como objeto de su ejercicio, esto es, se modifica al convertirse en biopoder, en la obra del autor romano no se reflexiona sobre las técnicas de poder específicas e históricamente determinadas, sino que la misma estructura de la soberanía establece desde su origen una relación con la vida, con la vida nuda. Esto es, desplaza la hipótesis del biopoder y la extiende a la naturaleza misma del poder soberano. Sin embargo, en estas líneas me centraré en la visión de Foucault y no en la de Agamben.

${ }^{14}$ La obra Giorgio Agamben es un intento de continuar la de Foucault, aunque incorpora elementos de Martin Heidegger, Walter Benjamin y Carl Schmitt que lo llevan a pensar que el sentido teológico de la economía es uno de los elementos para explicar el proceso de formación de la gubernamentalidad que, como indiqué en la nota anterior, supone una variación de los postulados de Foucault. Sin embargo, me parece que, para este asunto, los ejemplos de los que se sirve pueden ser de ayuda para pensar la nueva forma de gobernar que identifica la obra de Foucault (Agamben 1995, Agamben 2009 y Agamben 2016b).

${ }^{15}$ Otro de los ejemplos que creo que puede clarificar este tema es el del consu-

Revista de Filosofía Diánoia, vol. 65, no. 85 (noviembre de 2020-abril de 2021) e-ISSN: 1870-4913 • DOI: https://doi.org/10.22201/iifs.18704913e.2020.85.1845 
para Diogo Sardinha, el peligro y las respuestas para repelerlos bajo el régimen liberal se erigen en principios organizadores en el centro de la vida (Sardinha 2006, pp. 124-125). Esto es, de lo que se trataría sería de utilizar el argumento de la defensa de la libertad en nuestras sociedades mediante la introducción de dispositivos de control sobre los individuos que éstos tendrán que aceptar para sentirse en seguridad y para poder ser libres.

Con este tipo de mecanismos se consigue organizar y racionalizar los métodos de poder mediante la introducción de la categoría de "deseo" en las reflexiones en torno a la población. ${ }^{16}$ Foucault se refiere otra vez a Quesnay para explicar la introducción del deseo como categoría

mismo. Si nos fijamos en las sociedades actuales, veremos que, a diferencia de las que nos han precedido, en ellas no se producen objetos para satisfacer necesidades, sino que se crean necesidades en función de las categorías de la población para que se consuma lo que se produce.

${ }^{16}$ En los cursos en los que se ocupa de las técnicas de subjetivación ( $D u$ gouvernement des vivants (1979-1980), L'herméneutique du sujet (1981-1982) y Le Gouvernement de soi et des autres (1982-1983)), plantea que los individuos se piensan como seres que desean [êtres désirants] de manera autónoma; de ahí que estos mismos sujetos deban reconocer en su interior ese deseo verdadero mediante la introspección que les obliga a plantearse la pregunta sobre quién soy. Esta pregunta sitúa al individuo en una relación de dependencia porque la relación del sí mismo con la verdad del individuo que se hace la pregunta lo sujetan a un discurso que no le es propio, sino que es exterior. Éste es uno de los mecanismos que examina en su curso de 1979 a 1980, Du gouvernement des vivants, en el que centra parte de su análisis en el dispositivo de la confesión cristiana y en cómo éste obliga al individuo a la introspección y a la identificación del sí mismo con el relato de esa introspección. Este mecanismo secularizado en diferentes técnicas y disciplinas psicológicas es uno de los que garantiza la obediencia en la medida en que, por citar a Fréderic Gros, "cuando mejor se obedece es en el momento en el que se busca la identidad más íntima" (Gros 2013, pp. 57-64). Esto es, como sujeto deseante, cada individuo obtiene su propia identidad a partir de su propio deseo y, en cuanto éste es opaco para la conciencia misma de los individuos, sólo puede volverse transparente en una relación reglamentada con otra persona (ya sea un director, un confesor o un psicoanalista) bajo la forma de un monólogo indefinido que será escuchado - lo que me parece que hoy en día podríamos identificar con las redes sociales-. De esta manera, se hace creer a los individuos que lo que les afecta, sus problemas, sus miedos, etc., proviene del desconocimiento de ese deseo. El desvelamiento del mismo mediante su confesión crearía ese deseo y emplazaría al individuo en una relación de dependencia, a la vez que lo situaría en el horizonte de la obediencia. Dicho con otras palabras, el sujeto creerá conocerse a sí mismo mediante la introspección y la confesión de sus deseos ocultos, sin darse cuenta de que está siguiendo los anhelos de la masa por ser alguien. Esto es, para evitar ser un Don Nadie cada uno se definirá a sí mismo en función de patrones exteriores que lo que pretenden es la sujeción de los individuos mediante la normalización. 
propia de la población. Quesnay afirmó que no se le podía impedir a la gente "que fuese a vivir allí donde consideraran que podían conseguir más beneficio, en cuanto desean dicho beneficio" (Foucault 2004a, pp. 74-75), por lo que ahora el problema no sería el de impedirlo, sino de decir permitirlo y establecer los mecanismos que faciliten la consecución de dicho deseo, de tal manera que estimule y favorezca el amor propio para que se produzcan efectos beneficiosos para el Estado. De esta manera, el deseo termina por producir el interés general, pues el deseo será "la búsqueda del interés por parte del individuo" (Foucault 2004a, pp. 74). Y esta búsqueda por el interés será la que permitirá actuar de manera calculada sobre la población mediante la utilización del deseo en la producción del interés colectivo. Foucault señala que:

La población es un conjunto de elementos dentro del cual se pueden identificar constantes y regularidades, a la vez que permite detectar el universal del deseo que produce regularmente el beneficio de todos, y a propósito del cual se puede detectar un cierto número de variables de las cuales depende y que son susceptibles de modificarlo. (Foucault 2004a, p. 76)

La introducción del deseo permite pensar en las opiniones, las maneras de actuar, los comportamientos y los miedos de la población como datos empíricos. Esto hace que surja lo público como una esfera en la que se puede intervenir. Tal proceso implica que el significado de la categoría de población se ensanche desde sus vínculos con la biología en el sentido de especie humana hasta su superficie, lo público. Así, la categoría de lo público se toma en el sentido de un conjunto de datos que se obtienen de manera empírica y que permiten establecer los modelos a la hora de determinar los objetivos que se deseen alcanzar. ${ }^{17}$ De esta forma se deja atrás la manera en la que se piensa la relación de los individuos con la sociedad en los términos técnico-jurídicos como sujeto de derechos - propios a las reflexiones en torno a la soberanía- para pasar a concebir tal relación de manera técnico-política en función de parámetros considerados naturales y, por ende, sujetos a leyes identificables por las ciencias y manipuladas mediante diferentes técnicas.

${ }^{17}$ De la misma manera que el concepto de población se aplica en la producción de conocimiento sobre el Estado, lo hará en las disciplinas. Para Foucault, el paso de la gramática a la filología se produce en el momento en el que se estudian las lenguas de las poblaciones. Al igual que con la biología, Darwin plantea que la población es un nexo entre el medio y el organismo en la medida en que su explicación parte de la población como un elemento a través del cual el medio produce efectos sobre los organismos.

Revista de Filosofía Diánoia, vol. 65, no. 85 (noviembre de 2020-abril de 2021) e-ISSN: 1870-4913 • DOI: https://doi.org/10.22201/iifs.18704913e.2020.85.1845 
Nuestro autor explica este paso al sostener que el modelo teológico del "gobierno pastoral" propio de la tradición hebraico-cristiana se emplaza, en último término, en un lugar central a la hora de pensar el nacimiento del Estado como entidad moderna. El "gobierno pastoral" - ausente en el pensamiento clásico sobre la política que distinguía con claridad entre la oikonomía, de donde proviene el término "economía" y que hacía referencia a la gestión de las propiedades del déspotas, y la polis, que es el espacio de la política y, por ende, en donde se realiza la actividad del ciudadano o del polita- es uno de los orígenes del gobierno de la población. La gestión de recursos abole otras formas políticas, así que el modelo del gobierno pastoral, más técnico que jurídico, se adapta mediante la secularización y adaptación del mismo a la nueva entidad política que supone el Estado.

Foucault se interesa en cómo las técnicas de poder cambian desde el momento en el que la economía [oikonomía] y la política [polis] se integran la una en la otra, e identifica la aparición de los nuevos dispositivos biopolíticos en el instante en el que se plantea la cuestión sobre la "manera como se debe gestionar a los individuos, los bienes y las riquezas como se hace en el seno de las familias" (Foucault 1994b, pp. 641-642). Esta forma de gestión pasa por la introducción de la categoría de población como centro de la acción gubernamental. De esta forma, al igual que el pastor tiene que conocer a cada miembro de su rebaño para hacerlos marchar juntos, mediante la categoría de población la gubernamentalidad permite conocer a los individuos que componen la sociedad. Por lo tanto, se trata de un ejercicio del poder que se fundamenta en un saber a la vez individualizante y globalizador sobre los sujetos y la especie, y es en esa imbricación entre lo individual y lo global en donde se sitúa el dispositivo de la biopolítica.

\section{El mercado como elemento veridiccional}

Para Foucault, con el surgimiento del liberalismo la razón gubernamental comienza a transformarse por la puesta en práctica de mecanismos, tanto internos como externos, que no pretenden ahora asegurar el crecimiento en fuerza, riqueza o de poder del Estado, sino que tratan más bien de limitarlo desde el poder de gobernar (Foucault 2004b, p. 39). En ese momento, el mercado se convierte en el lugar de veridicción por excelencia. Ahora será la entidad a partir de la que se juzgarán las labores gubernamentales.

El mercado se presenta en esta época como algo natural que no se puede modificar sin caer en el riesgo de desnaturalizarlo. A la vez,

Revista de Filosofía Diánoia, vol. 65, no. 85 (noviembre de 2020-abril de 2021) e-ISSN: 1870-4913 • DOI: https://doi.org/10.22201/iifs.18704913e.2020.85.1845 
ocupa el lugar en el que se fijan los precios, los "buenos precios" como dirían los fisiócratas, o el "precio natural" en palabras de Boisguilbert (Foucault 2004b, p. 33), que en último término se convertirán en el valor. Con el empleo del patrón del mercado, los discursos comienzan a determinar cuáles son los límites "buenos" de la actuación estatal en función de los objetivos de la gubernamentalidad (Foucault 2004b, p. 41). En este sentido, Foucault piensa que a partir del siglo XIX la utilidad, vinculada con el deseo en la forma en la que me referí antes, comienza a entremezclarse con los temas tradicionales del derecho. La utilidad funge entonces como axioma del discurso veridiccional que determina los intereses de lo público, a la vez que pone límites a las actuaciones de los Estados.

De ahí que, según Foucault, las relaciones entre los intereses colectivos y los individuales se conviertan en el centro del gobierno, es decir, "el gobierno en esta nueva razón gubernamental es algo que manipula los intereses", lo que implica, en última instancia, un retroceso del Estado en favor del biopoder, como forma de poder que se ejerce sobre la vida de los individuos. Este desplazamiento permite la aparición de un discurso veridiccional que, a partir de la racionalidad inherente al mismo Estado, termina por autolimitar al propio Estado en función del límite que representa el mercado, el cual se concibe ahora como una entidad que regula las pasiones (Foucault 2004a, pp. 118-123).

Este paso está marcado por la extensión y el disimulo de formas de control difusas que pretenden gobernar las acciones de los individuos tanto en el plano colectivo como en el individual. Esas formas de control implican que el Estado se retrotraiga en favor del mercado y de la producción industrial, y su finalidad no será otra, según el orden del discurso que le otorga el grado de verídico, que la de generar una fuerza de trabajo dócil a partir de diferentes microdispositivos de poder. Justo aquí surge la biopolítica como una técnica de gobierno, como la coordinación estratégica de elementos diversos que garantizan una subjetivación política concreta.

Al igual que en el cristianismo — que da forma al poder pastoralse pide la sumisión como forma de voluntad, el liberalismo solicita la interiorización de la sumisión y de la normatividad. No se pretende que la voluntad se confunda con la ley, sino que la sumisión se acepte por la voluntad del individuo mediante formas difusas de control, vinculadas con la esfera social, y gracias a los discursos que las vuelven verdaderas; es decir, que son los discursos los que emplazan en un lugar concreto a los individuos en la sociedad y dichos lugares serán aceptados por los individuos devenidos sujetos. Esta forma de gobernar a los indivi-

Revista de Filosofía Diánoia, vol. 65, no. 85 (noviembre de 2020-abril de 2021) e-ISSN: 1870-4913 • DOI: https://doi.org/10.22201/iifs.18704913e.2020.85.1845 
duos parte de la creación de conocimientos sobre ellos mismos y toma como punto de referencia las normas disciplinarias, el cual se vincula de manera difusa con el conjunto de datos sobre las poblaciones que viven en ese Estado. A partir de esto, las vidas de la población se consideran problemas políticos a resolver desde los planteamientos de los discursos de la economía (Revel 2008, p. 25). Por lo tanto, entender esos discursos nos permite saber cómo hemos llegado a ser lo que somos y, con ello, resistir a una forma de subjetivación que nos ha sido impuesta.

En su curso de 1978, Naissance de la biopolitique, Foucault examina el cambio epistemológico que comienza con el liberalismo clásico (o protoliberalismo) de Adam Smith y los fisiócratas, para mostrar los momentos en los que el mercado irrumpe como discurso veridiccional con respecto a las formas de gobernar y a las limitaciones del poder estatal. Este desplazamiento provoca que se comience a desconfiar del Estado y que aparezca en los liberales lo que Foucault denomina "fobia del Estado", una fobia que reaparece con fuerza en los discursos neoliberales que surgen en Alemania y Austria tras el nazismo (Foucault 2004b, pp. 53-63).

La reacción ante el nazismo y el estalinismo de la que nos habla Foucault provoca que los autores germanos busquen fundamentar el Estado en otra entidad que no sea el Estado ni la nación. De ahí que desarrollen sus fundamentos en el mercado. Tales tesis emigran a Estados Unidos de la pluma de Fiedrich Von Hayek y otros, y terminan por influir en la Escuela de Chicago que desarrolla una teoría análoga. En este sentido, los discursos veridiccionales que generan estos movimientos se fundamentan en la limitación de las actuaciones estatales y en la maximización de beneficios, bajo la hipótesis de que cualquier interferencia voluntaria en la sociedad o el mercado por parte del Estado conduce a la sociedad ineluctablemente hacia la servidumbre y el totalitarismo (Hayek 2013).

A diferencia de los del liberalismo clásico, estos postulados del siglo XX no pretenden que el mercado sea una entidad natural a la que se le debe dejar actuar por sí misma. El Estado debe influir en el mercado para favorecer la competencia. De ahí que, si en el siglo XVIII se apelaba al valor veridiccional de la utilidad para fabricar los intereses y operar sobre el deseo, con la llegada de los neoliberales el valor veridiccional continúa anclado en la lógica del mercado, pero ahora lo que se tiene en cuenta es la maximización de beneficios a partir de la competencia, que a su vez debe ser motivada por el mercado, así como estimulada y protegida por el Estado.

Revista de Filosofía Diánoia, vol. 65, no. 85 (noviembre de 2020-abril de 2021) e-ISSN: 1870-4913 • DOI: https://doi.org/10.22201/iifs.18704913e.2020.85.1845 
En el análisis de Foucault de la biopolítica se muestra cómo los neoliberales estadounidenses aplican los análisis económicos a dominios que, como norma general, se encontraban fuera de este tipo de estudios y que se relacionaban antes con las conductas, como es el caso del matrimonio, la educación de los niños, etc. (Foucault 2004b, p. 271). Nos encontramos, por lo tanto, con la extensión de un discurso veridiccional a otros dominios propios de la vida humana gracias a la categoría de población que acaba por interiorizarse. Este tipo de discurso termina por definir "La conducta racional [como] aquella que es sensible a modificaciones en las variables del medio y que responde de manera no aleatoria y, por lo tanto, sistemática, por lo que la economía se podría definir como la ciencia de la sistematicidad de las respuestas a las variables del medio" (Foucault 2004b, p. 273). Así, para Foucault la ciencia social que es capaz de generar un conocimiento sobre lo que se debe o no hacer es la economía en su vertiente neoliberal, porque sus métodos se aplican para entender y justificar la racionalidad de las vidas de los individuos que viven bajo Estados que aplican políticas de carácter neoliberal.

El hecho de que los Estados se funden sobre el mercado y que, al mismo tiempo, el mercado tenga un papel preponderante en relación con la veridicción de las acciones del Estado, provoca que se limite el poder del soberano, es decir, de los que detentan poder en favor de los dominios económicos. A su vez, el discurso de la gestión de recursos deviene el discurso veridiccional de las entidades estatales. ${ }^{18}$

Una vez que alcanza este punto, Foucault desarrolla una crítica al concepto de sociedad civil ${ }^{19}$ en su acepción moderna en los siguientes términos:

La sociedad civil es como la locura o la sexualidad, es decir, son realidades de transacción, a saber, se sitúan en el juego y en las relaciones de poder de eso que, al mismo tiempo, se les escapa [...]. Sociedad civil, entonces, como elemento de la realidad transaccional, me parece que es algo completamente correlativo de las técnicas de tecnología gubernamental que se denominan liberalismo, es decir, una tecnología de gobierno que

${ }^{18}$ La utilización de los métodos de la gestión empresarial ha impregnado gran parte de la política actual. Baste referirnos a La gobernanza europea. Un libro blanco, en el que se introduce el propio concepto de gobernanza proveniente de la noción de management (Estévez Araujo 2018).

${ }^{19}$ Recordemos que Cicerón utilizó el concepto de "sociedad civil" para traducir la koinonia politike griega, y que el término reaparece con la escuela escocesa de la pluma de Adam Ferguson.

Revista de Filosofía Diánoia, vol. 65, no. 85 (noviembre de 2020-abril de 2021) e-ISSN: 1870-4913 • DOI: https://doi.org/10.22201/iifs.18704913e.2020.85.1845 
cuenta con el objetivo de su propia autolimitación en la misma medida en la que se ajusta a la especificidad de los procesos económicos. (Foucault 2004b p. 301)

Como vemos, el concepto de "sociedad civil" está destinado a dotar de valor veridiccional a los discursos mercantiles propios del liberalismo y a encauzar en los intercambios lo que las relaciones de poder no pueden integrar con la categoría de Estado. Esta esfera la conciben los neoliberales como un espacio en el que los individuos buscan satisfacer libremente sus intereses; sin embargo, Foucault, como veíamos, entiende que éstos están predeterminados no por los sujetos emplazados en dicho espacio o por las actividades que realizan, sino por los diferentes mecanismos disciplinarios que ahora reciben un apoyo discursivo en la economía, que se concibe como la ciencia que permite sujetar y dirigir los deseos de los individuos en la sociedad civil.

Sin embargo, el hecho de que la sociedad civil se piense como una entidad opuesta o excluyente del gobierno da cuenta de una de las estrategias de la racionalidad gubernamental del liberalismo. Si se concibe la sociedad civil de esta manera, entendemos cómo se sobrentiende que ésta nace de las técnicas gubernamentales; a fin de cuentas, es la forma de gobierno la que crea la sociedad civil para poder así garantizar de manera jurídica la economía fundada en la producción y el intercambio, sin interferencias estatales que obstruyan la libre circulación de mercancías y servicios. ${ }^{20}$

En este sentido, Foucault arguye que la idea del mercado controlado por sí mismo o que se deja a sus propias reglas y se regula por la mano invisible, además de ser el desarrollo secular de la idea de providencia que propagaron los teólogos cristianos, implica la introducción del egoísmo como una actitud positiva en la medida que implica aceptar que el interés privado armoniza con el interés común en cuanto que los individuos, al buscar su propio lucro, generan el beneficio común. Este argumento teológico secularizado legitima discursos que pretenden que los individuos devengan sujetos empresarios; sujetos cuyos deseos se enfocan en maximizar y potenciar sus propios recursos mediante el modelo de la empresa. Así, cada sujeto deberá trabajarse a sí mismo para conseguir ser un "emprendedor de sí mismo" que podrá circular por el espacio de la sociedad civil e introducir sus deseos en la lógica del intercambio. Mientras tanto, el Estado no osará entrar directamente en

${ }^{20}$ Para Wendy Brown, estos mecanismos propios de la democracia liberal implican un proceso de desdemocratización al centrarse en la simple gestión y en la gobernanza (Brown 2007).

Revista de Filosofía Diánoia, vol. 65, no. 85 (noviembre de 2020-abril de 2021) e-ISSN: 1870-4913 • DOI: https://doi.org/10.22201/iifs.18704913e.2020.85.1845 
la esfera de la sociedad civil, aunque sí que la protegerá para garantizar la libre competencia de las empresas y de los individuos entre sí. Este modelo del "emprendedor de sí mismo" en competencia con los otros, y que describe Foucault, es uno de los elementos que, según Christian Laval, nos permite identificar las derivaciones de la gubernamentalidad en las sociedades occidentales del presente (Foucault 2004b, p. 232). Para Laval, las consecuencias de este modelo, cuyos argumentos se utilizan en la actualidad para luchar contra los efectos de la desaparición del empleo, han provocado que los individuos se piensen a sí mismos como si fueran capital humano y ya no como ciudadanos (Laval 2018, pp. 126-129).

Se trata de un paternalismo en forma de seguridad e incitación de la competencia que preforman subjetividades propias de un yo empresarial, que el mismo individuo desea y que sirven para garantizar una forma de obediencia que implica una reducción de costes, una forma de gobernar más y de manera más eficaz al menor precio posible. El mecanismo es el siguiente: el sujeto, creyendo que conoce su deseo, busca alcanzar lo que quiere la masa, mientras que, para garantizar su seguridad, es transparente frente al Estado. Ahora bien, el discurso del modelo neoliberal provoca que el individuo se transforme en un sujeto racional mediante el reconocimiento, en cuanto deseo que le es propio, de la posibilidad de explotar al máximo sus capacidades, de gestionar sus pasiones con respecto a fines determinados, de desarrollar y optimizar sus recursos mentales para maximizar sus beneficios con el menor coste posible. Así, el sujeto interioriza los dispositivos que le dan forma y que lo emplazan en el horizonte de la obediencia a un poder exterior, creyendo que ejerce su libertad de manera singular.

Técnicas de resistencia como formas de producción del yo

La ontología del presente que desarrolla Foucault lo lleva a afirmar que las técnicas de resistencia a las relaciones de poder injustas provocadas por las prácticas de estatización pasan por comprender cómo se han formado. Y es en este sentido en el que a mi juicio se pueden interpretar los deseos de Foucault de escribir un "libro bomba", un libro que le sería útil a alguien en un momento determinado y que desaparecería después. $^{21}$

\footnotetext{
${ }^{21}$ En la presentación del número de Critique dedicado a Foucault, Philippe Roger recuerda la anécdota de cuando Foucault presumía delante de sus estudiantes californianos sus intenciones de crear un libro bomba que, tras explotar, sirviera
}

Revista de Filosofía Diánoia, vol. 65, no. 85 (noviembre de 2020-abril de 2021) e-ISSN: 1870-4913 • DOI: https://doi.org/10.22201/iifs.18704913e.2020.85.1845 
Ese "libro bomba" nos permitirá comprender cómo la objetivación de los individuos los constituye con una subjetividad concreta que busca asegurar su obediencia, pero no la obediencia en el sentido de que el soberano le prohíba realizar algo, sino, al contrario, que lo incite a hacer algo que en principio desea y cuyos efectos puede gestionar en su propio beneficio. Comprender ese proceso y sus mecanismos nos permitiría obstaculizar los dispositivos que nos inducen a actuar de cierta manera y no de otra. Se trataría de comprender los procesos de estatización para desvelar los dispositivos que nos hacen ser como somos y poder liberarnos de nosotros mismos y, por ende, del tipo de individualización que le es propio a la gubernamentalidad en su versión neoliberal (Morey 2014b, p. 320).

En 1977, Foucault planteó que "[e]s falso decir con cierto posthegelianismo que la existencia concreta del hombre sea el trabajo, ya que la vida y el tiempo del hombre no son por naturaleza trabajo, son placer, discontinuidad, fiesta, reposo, necesidades, apetitos, violencias, depredaciones, etc." (Foucault 2001a, pp. 233-234). En este sentido, podemos afirmar que las técnicas de resistencia sirven para desvelar esa forma de vida que se sitúa más allá del devenir empresario de sí mismo que nos propone nuestro presente. Se trataría de comprender para después obstaculizar las formas de subjetivación y los dispositivos que convierten a los individuos en sujetos convencidos de que su naturaleza pasa por el trabajo.

Sin embargo, Foucault plantea que se debe realizar un análisis y una crítica que en gran parte no habían sido desarrollados en su época; y no sólo, ya que, en sus propias palabras, también se deben inventar "las estrategias que permitirán modificar las relaciones de fuerza", para así coordinarlas de manera que la "modificación sea posible y se pueda inscribir en la realidad". A continuación señala que "el problema no es el de definir una posición política (lo que implicaría elegir dentro de un tablero político ya determinado), sino de imaginar y de hacer existir nuevos esquemas de politización". A su juicio, no vale la pena politizarse en organizaciones ya hechas, pues a las nuevas y "grandes técnicas de poder (que corresponden a las economías multinacionales o a los Estados burocráticos) deberán oponérseles formas de politización totalmente nuevas" (Foucault 1994a, pp. 233234). Nos insta a resistir mediante la invención de nuevas formas de politización; resistencia que es intrínseca a las mismas relaciones de poder y es posible gracias a ellas. Lo que quiero decir es que, como para recordar a la gente que esos libros habían producido unos fuegos artificiales preciosos (Roger 2016, p. 963).

Revista de Filosofía Diánoia, vol. 65, no. 85 (noviembre de 2020-abril de 2021) e-ISSN: 1870-4913 • DOI: https://doi.org/10.22201/iifs.18704913e.2020.85.1845 
él mismo afirma, en una entrevista con Jacques Rancière (Foucault 1994a, p. 425), no existen relaciones de poder sin resistencia a los poderes porque la resistencia es inherente a las relaciones de poder. Más aún, la resistencia se forma y se ejerce en el mismo lugar que las relaciones de poder, por lo que las técnicas de resistencia son, al igual que el poder, integrables en estrategias globales (Foucault 1994a, p. 791).

Con todo, a pesar de que planteó la posibilidad de estrategias globales, Foucault se interesó sobre todo por "el movimiento mediante el cual un solo hombre, un grupo, una minoría o un pueblo entero dice: Dejo de obedecer; y se enfrenta al poder poniendo en riesgo su vida", pues, en su opinión, "el hombre que se subleva no cuenta con una explicación, necesita arrancar e interrumpir el hilo de la historia y las largas cadenas de razones" que lo llevan a preferir el riesgo de morir a la certeza de obedecer. Y a continuación asienta que su moral teórica es antiestratégica en cuanto que "es respetuosa cuando una singularidad se enfrenta a la universalidad del poder". ${ }^{22}$

De lo que se trata es de enfrentarse a la racionalidad desde formas de singularidad no reconocidas por los procesos de estatización y que rechacen el tipo de individualidad que nos ha sido impuesto; esto es, emprender luchas para hacer valer nuestro derecho a ser diferentes y verdaderamente individuales. Para ello, plantea que:

[N]o existe una salida práctica a la idea de un sujeto que no nos viene dada de antemano, debemos hacer de nosotros mismos una obra de arte [...]. No se trata de unir la actividad creadora de un individuo a la relación que mantiene consigo mismo, sino de unir esa relación consigo mismo a una actividad creadora. (Foucault 1994a, pp. 186-193)

Así, el autor plantea una estética de la existencia que, al ir más allá de los términos exclusivamente estéticos, se sitúa en el plano de la ética (Agamben 2016a, pp. 102-103).

Mediante la introducción de esta estética de la existencia ${ }^{23}$ en forma de ética, lo que Foucault logra es dar forma a una subjetividad que se distancia de la realidad de una forma que nada tiene que ver

${ }^{22}$ La obra del Comité Invisible ofrece una apología de esos sucesos en los que los individuos desobedecen a los discursos establecidos y ponen su integridad en peligro motivados por contrarrestar la universalización del poder.

${ }^{23}$ Para explicar el souci-de-soi, Foucault se sirve en los últimos momentos de su vida de la expresión "estética de la existencia" (Foucault 1994b, pp. 186-193).

Revista de Filosofía Diánoia, vol. 65, no. 85 (noviembre de 2020-abril de 2021) e-ISSN: 1870-4913 • DOI: https://doi.org/10.22201/iifs.18704913e.2020.85.1845 
con una actitud solitaria, sino con la posibilidad de la acción. Plantea una distancia entre el sujeto y la realidad que evita la fascinación por lo inmediato, y ello le permite reflexionar distanciándose de la individualidad de casos concretos que genera la totalidad propuesta por el proceso de estatalización. Frente al modelo del psicoanálisis en el cual el sujeto se construye mediante la introspección y el reconocimiento del deseo oculto, o el modelo de la gestión en el cual el individuo se vuelve sujeto mediante la interiorización de los valores empresariales, Foucault plantea otro tipo de sujeto, un sujeto ético que pueda resistir. Un sujeto que no tenga que conocerse a sí mismo, sino que debe hacerse; es decir, no se trataría de conocer la verdad sobre nosotros mismos, sino de prepararnos con la ética, una ética fundada en el "cuidado de sí" que Foucault encuentra en la Antigüedad.

El "cuidado de sí" nos proporcionaría armas en forma de enunciados para los momentos críticos. El sujeto del que nos habla inspirándose en la Antigüedad es un sujeto más que nada práctico que nos permite construirnos y cuidarnos a través de una forma diferente de relación con nosotros mismos y con los otros. Según Frédéric Gros, este sujeto ético crearía con la ayuda de otros reglas de vida como, por ejemplo, ejercicios prácticos para no enfadarse o para sosegar las pasiones; reglas de vida que permitan a los individuos ser fieles a sus principios mediante el emplazamiento de la ética en la construcción de la relación consigo mismos y con los otros pensados como "sí mismos". El problema no sería tanto intentar que el discurso del sujeto refleje en forma fiel la riqueza interior o una verdad oculta, sino de ejercitar el discurso para que le dé forma a la exterioridad de las acciones. Por lo tanto, se trataría de liberarse de la forma de individualización, aunque también de la totalización, impuestas mediante los procesos de estatización gracias a la creación ética de nosotros mismos.

De ahí que, según mi interpretación de la obra de Foucault, sí es posible producir subjetividades alternativas que no sean efectos del poder, sino de su par, a saber, de la resistencia ética a lo intolerable y propia del "cuidado de sí". Las formas de resistencia a las que nos referimos deberían tener en cuenta los peligros del liberalismo y del neoliberalismo, y tomar ese diagnóstico del presente como base para fundar una estética de la existencia. Ya no se trataría de esperar al mesías de la revolución social, sino de pensar la libertad como un problema estratégico, de pensar en formas de subjetivación que puedan brotar del "cuidado de sí" en contraposición al "conócete a ti mismo" y que, en su lugar, den cabida a un sujeto que no se centre en sí mismo de

Revista de Filosofía Diánoia, vol. 65, no. 85 (noviembre de 2020-abril de 2021) e-ISSN: 1870-4913 • DOI: https://doi.org/10.22201/iifs.18704913e.2020.85.1845 
manera introspectiva, sino más bien en el sentido de la articulación de un sujeto que actúa conforme a sus principios de acción, principios que sirvan, como señala Foucault en Qu'est-ce que la critique? al "arte de la inservidumbre voluntaria", o de la "indocilidad reflexionada" que nos permita liberarnos de nosotros mismos y, sin romper los lazos con los otros, gozar del derecho a ser diferentes en una relación entre los "sí mismos" (Foucault 2015). ${ }^{24}$

\section{Referencias bibliográficas}

Agamben, Giorgio, 1995, Homo sacer. Il potere sovrano e la nuda vita, Einaudi, Turín.

Agamben, Giorgio, 2009, Il regno e la gloria. Per una genealogia teologica dell' economia e del governo. Homo sacer II, 2, Bollati Boringhieri, Turín.

Agamben, Giorgio, 2016a, El fuego y el relato, trad. Ernesto Kavi, Sexto Piso, México/Madrid.

Agamben, Giorgio, 2016b, "De qué manera la obsesión por la seguridad transforma la democracia", trad. Hero Suárez, Reportes Sexto Piso, no. 28, disponible en $<$ http://reportesp.mx/de-que-manera-la-obsesion-por-la-seguridadtransforma-la-democracia-giorgio-agamben $>$.

Aaron, Raymond y Michel Foucault, 2007, Dialogue, Lignes, París.

Balibar, Etienne, 2015, "L'anti-Marx de Michel Foucault", en Christian Laval (comp.), Marx et Foucault, La Découverte, París.

Brown, Wendy, 2007, Les habits neufs de la politique mondiale. Néolibéralisme et néoconservatisme, trad. Georges Blumberg, Les Praies ordinaires, París.

Comité Invisible, 2017, Maintenant, La fabrique, París.

Comte, Auguste, 1851, Système de politique ou traité de sociologie instituant la religion de l'humanité, La Librairie scientifique industrielle, París.

De Lagasnerie, Geoffroy, 2012, La dernière leçon de Michel Foucault. Sur le néolibéralisme, la théorie et la politique, Fayard, París.

De Lagasnerie, Geoffroy, 2013, "Néolibéralisme. Théorie politique et pensée critique", Raisons politiques, no. 42, disponible en <https://doi.org/10.3917/ rai.052.0063>.

Deleuze, Gilles, 2004, Foucault, Les Éditions de Minuit, París.

Estévez Araujo, José Antonio, 2008, "Que no te den gobernanza por democracia", Mientras tanto, nos. 108-109.

Fassin, Didier, 2017a, L'ombre du monde. Una anthropologie de la condition carcérale, Points, París.

Fassin, Didier, 2017b, Punir, une passion contemporaine, Seuil, París.

Fassin, Didier, 2018, La vie. Mode d'emploi critique, Seuil, París.

${ }^{24}$ Deseo agradecer a los y a las evaluadoras de la revista Diánoia por sus aportaciones para mejorar el presente artículo.

Revista de Filosofía Diánoia, vol. 65, no. 85 (noviembre de 2020-abril de 2021)

e-ISSN: 1870-4913 • DOI: https://doi.org/10.22201/iifs.18704913e.2020.85.1845 
Foucault, Michel, 1975, Surveiller et punir. Naissance de la prison, Gallimard, París.

Foucault, Michel, 1989, Résumé de cours. 1970-1982, Julliard, París.

Foucault, Michel, 1994a, Dit et écrits III (1976-1979), Gallimard, París, <https: //doi.org/10.14375/NP.9782070739882>.

Foucault, Michel, 1994b, Dits et écrits IV (1980-1988), Gallimard, París. <https: //doi.org/10.14375/NP.9782070739899>.

Foucault, Michel, 1997, Il faut défendre la société. Cours au Collège de France (1975-1976), Gallimard/Seuil, París.

Foucault, Michel, 2001a, Dits et écrits II (1954-1975), Gallimard, París.

Foucault, Michel, 2001b, L'herméneutique du sujet. Cours au Collège de France (1981-1982), Gallimard/Seuil, París.

Foucault, Michel, 2004a, Sécurité, population, territoire. Cours au Collège de France (1977-1978), Gallimard/Seuil, París.

Foucault, Michel, 2004b, Naissance de la biopolitique. Cours au Collège de France (1978-1979), Gallimard/Seuil, París.

Foucault, Michel, 2008, Le gouvernement de soi et des autres. Cours au Collège de France (1982-1983), Gallimard/Seuil, París.

Foucault, Michel, 2012, Le gouvernement des vivants. Cours al Collège de France (1979-1980), Gallimard/Seuil, París.

Foucault, Michel, 2015, Qu'est-ce que la critique? Suivie de La culture de soi, P. Vrin, París.

Gros, Frederick, 2013, "Le gouvernement de soi", en Michel Foucault et al., Pensées rebelles. Foucault, Derrida, Deleuze, Sciences Humaines, París, <https:// doi.org/10.3917/sh.colle.2013.02.0057>.

Hayek, Fiedrich von, 2013, La Route de la servitude, trad. Georges Blumberg, Presses Universitaires de France, París, <https://doi.org/10.3917/puf. hayek.2013.02>.

Hobbes, Thomas, 1971, Léviathan. Traité de la matière, de la forme et du pouvoir de la république ecclésiastique et civile, trad. Mikaël Garandeau y Eric Marquer, Sirey, París.

Laval, Christian, 2018, Foucault, Bourdieu et la question néolibérale, La Découverte, París.

Lazzarato, Maurizzio, 2000, "Du biopouvoir a la biopolitique", Multitudes, vol. 1, no. 1, pp. 45-57, <https://doi.org/10.3917/mult.001.0045>.

Le Blanc, Guillaume y Jean Terrel (comps.), 2003, Foucault au Collège de France: un itinéraire, Presses Universitaires de Bordeaux, Pessac.

Lefort, Claude, 1972, Le travail de l'œuvre. Machiavel, Gallimard, París.

Morey, Miguel, 2014a, Escritos sobre Foucault, Sexto Piso, México/Madrid.

Morey, Miguel, 2014b, Lectura de Foucault, Sexto Piso, México/Madrid.

Raimondi, E. (comp.), 1982, Opere di Niccolò Machiavelli, Ugo Mursia, Milán.

Revel, Judith, 2008, Dictionnaire Foucault, Ellipses, París.

Roger, Philippe, 2016, "Un très beau feu d'artifice", Critique, no. 835, París, pp. 963-964, <https://doi.org/10.3917/criti.835.0963>.

Revista de Filosofía Diánoia, vol. 65, no. 85 (noviembre de 2020-abril de 2021) e-ISSN: 1870-4913 • DOI: https://doi.org/10.22201/iifs.18704913e.2020.85.1845 
Sardinha, Diogo, 2006, "Michel Foucault et les dangers du libéralisme" Les Études Philosophiques, no. 76, pp. 121-125 <https://doi.org/10.3917/leph. 061.0121>.

Vargas Zamora, Daniel (coord.), 2014, Critiquer Foucault. Les années 1980 et la tentation néoliberale, Les éditions Aden, Bruselas.

Recibido el 12 de abril de 2018; revisado el 29 de septiembre de 2019; aceptado el 11 de febrero de 2020. 